\title{
SEISMIC FORCES IN BASE-ISOLATED MASONRY STRUCTURES
}

\author{
M.J.N. Priestley*, R.L. Crosbie** and A.J. Carr*
}

\section{ABSTRACT}

Dynamic analyses of four, eight and twelve storey masonry shear walls supported on base-isolation systems are described. Each wall was modelled as a multi-degree-of-freedom cantilever. Results are presented which indicate behaviour is more complex due to the significance of higher mode effects, than was previously believed on the basis of simple single-degreeof-freedom models.

The influence of different types of base-isolation, and of the stiffness of the gravity supporting system, are discussed. Tentative design recommendations are proposed which provide a substantial reduction in design forces for short period structures while still maintaining an adequate margin of safety against the formation of wall hinges.

\section{INTRODUCTION}

The lack of confidence of Structural Engineers in the suitability of reinforced masonry as a structural material providing primary seismic resistance of buildings is reflected in current codes of practice. Capacity design procedures, coupled with the provisions of the New Zealand Loadings Code (1) imply high seismic shear coefficients for masonry shear walls, while the proposed draft Masonry Code(2) imposes severe limitations on the design shear stresses. The result has been to limit the size and type of masonry buildings which can be designed for New Zealand conditions.

In a recent paper ( 3 ), one of the authors showed that the limitations on maximum shear stress were unrealistic, and that substantially higher ultimate shears should be allowed for properly designed structures. This would have the effect of increasing the scope for design of masonry buildings. An alternative proposal is examined in this paper: limiting the shear force in masonry buildings by seismic base-isolation.

Base isolation is achieved by providing a short 'soft-storey' between the base of the building and the foundation, as illustrated in Fig. 1. The soft-storey consists of specially manufactured devices (Mechanical Energy Dissipators), generally of steel or lead, designed to have a lower shear capacity. than the supported structure, and capable of dissipating substantial amounts of energy by inelastic deformations. By judicious choice of isolator characteristics the accelerations to which the building is subjected may be kept low, and it should be possible to ensure that the masonry structural elements remain elastic under even very severe seismic attack. Because of the low response accelerations (limited by the capacity of the Mechanical Energy Dissipators) non-structural damage should be minimized, and structural damage

* Senior Lecturer in Civil Engineering, University of Canterbury.

** Assistant Engineer, Duffill Watts \& King, Consulting Engineers, Dunedin. confined to the isolators, which can be repaired or replaced at comparatively low cost $(4)$.

A considerable body of research has been compiled over recent years on the properties of different base-isolation systems. Of particular importance is the work that has been carried out at the Physics and Engineering Laboratory (P.E.L.) of the Department of Scientific and Industrial Research $(5,6,7,8)$. The devices investigated include

(a) rolling-bending of U-shaped steel strips (b) torsion of rectangular steel bars

(c) flexure of steel cantilevers

(d) extrusion of lead.

Typically the energy absorption characteristics of steel dampers of the first three categories above are described by Ramberg-Osgood type hysteresis, shown in Fig. 2(a), but for design purpose it is sufficiently accurate to represent the material behaviour by bi-linear elastoplastic hysteresis illustrated in Fig. 2(b). The extrusion of lead results in energy absorption characteristics best represented by the rigid-perfectly plastic hysteresis of Fig. 2(c).

Continuing work near completion at D.S.I.R., P.E.L., is expected to result in lead devices with omnidirectional characteristics similar to those of lead extrusion(13).

Although the properties of energy dissipation devices have received a lot of research attention, surprisingly little emphasis has been placed on the detailed examination of the response of realistic base-isolated structural models to seismic motions. Published work by Skinner and McVerry (4) has assumed that dynamic response would be comparatively simple, and may adequately be represented by an equivalent one-degree-of-freedom model. This model led the writers to claim that base-isolation would impart a degree of standardization of response to different earthquakes, and that there was a simple and direct relation- 
ship between level of isolation and level of response.

This paper examines the seismic response of three brick masonry buildings of different characteristics, with and without baseisolation devices, with the aims of critically examining the effects of assumptions made by previous researchers, and providing recommendations for design of base-isolated structures. Two types of energy dissipator are considered: flexure of steel cantilevers, and deformation of lead. These appear to be the most suitable for building application, as both can be designed for omnidirectional attack within the horizontal plane. Fig. 3 shows a possible method of incorporating the cantilever device for base isolation. Elastomeric bridge-bearings are mounted separate from the flexural beams and carry the building dead weight. The two vertical cantilevers are circular in section, tapered in length to provide a spread of plasticity (and thus reduce strain-hardening and peak strain levels) and are connected by a sliding sleeve arrangement. With the lead deformation device an elastomeric bearing also carried building weight, and is sufficiently flexible to sustain the relative movements between building base and foundation imposed by the plastic deformations of the lead.

\section{DESCRIPTION OF STRUCTURES ANALYSED}

\subsection{Wall Dimensions}

Three structures, each of which represented a Masonry Shear Wall taken from a four, eight or twelve storey building respectively, were analysed. The twelve storey masonry building is not necessarily considered to be a realistic possibility, but was felt to represent a reasonable upper limit for base-isolated masonry structures under seismic conditions.

\section{Structure A: 4-storey shear wall}

Fig. $4(a)$ shows the floor plan of a four storey masonry building designed by a firm of Christchurch Consulting Engineers. The wall selected for analysis, marked in Fig. 4(a) has height $11.2 \mathrm{~m}$, width $5 \mathrm{~m}$, and an aspect ratio of 2.24. Floor masses, shown in the elevation of Fig. 4(a), were based on 'hand' calculations for the distribution of seismic floor forces to the various vertical elements, taking torsional effects into account. Thus at any level,

$\mathrm{m}_{\mathrm{Al}}=\mathrm{m}_{\mathrm{T} \ell} \times \frac{\mathrm{F}_{\mathrm{Al}}}{\mathrm{F}_{\mathrm{T} \ell}}$

where $\mathrm{m}_{\mathrm{Al}}=$ seismic mass distributed to wall A at level $\&$

$\mathrm{m}_{\mathrm{T} \ell}=$ total seismic mass at level $\ell$

$F_{A l}=$ design seismic force on wall $\mathrm{A}$ at level $\ell$

$\mathrm{F}_{\mathrm{T} \ell}=$ total design seismic force at level \&

The forces $F_{A l}$ and $F_{T l}$ were based on the provisions of NZS 4203:1976(1). The structure represented a general usage office block, and a seismic live load of $0.8 \mathrm{kPa}$ was assumed.
Structures B and C: 8 and 12-storey shear Walls

The floor plan of Fig. 4(b) was simplified from an existing eight storey masonry apartment building in Christchurch, and was adopted for both structures $B$ and C. A typical $5 \mathrm{~m}$ long wall was modelled and considered to support masses in proportion to the tributary floor area for lateral loads, assuming all flanges were ineffective. A seismic live load of $1 \mathrm{kPa}$ was taken to be appropriate for these structures, resulting in the final floor masses shown in Fig. 4(b). Total wall heights were $21.6 \mathrm{~m}$ and $32.4 \mathrm{~m}$ for structures $B$ and $C$ respectively.

Note that both structural systems represented by Fig. 4 consist of masonry shear walls and flexible floor slabs. It is reasonable, and conservative, to assume that the floor slab acts purely as a diaphragm, and is incapable of providing significant moment coupling between adjacent shear walls. Consequently, all three walls analysed were assumed to be pure cantilever shear walls.

\subsection{Wall Stiffness - Building Period}

Recent research (3) has indicated that the flexural and shear stiffness of masonry walls should be based on effective Modulus of Elasticity $E_{m}$ of $5 \mathrm{GPa}$, and the uncracked section dimensions. This results in conservative (stiff) values for cracked walls, and was adopted for the analyses described below. 'Hand' calculations resulted in fundamental building periods of $0.22 \mathrm{sec}$, $0.95 \mathrm{sec}, 2.20 \mathrm{sec}$ for the 4,8 and 12 storey walls respectively. These values were approximately $10 \%$ higher than subsequently predicted by the computer analyses. It will be noted that a value of $10 \mathrm{GPa}$ is more commonly used for $E_{\mathrm{m}}$, and implies fundamental building periods approximately $29 \%$ lower than those resulting from the above assumptions.

\section{COMPUTER SIMULATIONS}

A computer program developed by Sharpe (9) and extended by Taylor (10) was used for dynamic inelastic (non-linear) time-history analyses of wall forces and displacements. Excitation was provided by a digitised acceleration record of the N-S component of the May 1940 El Centro earthquake.

\subsection{Distribution of Wall Moment Capacities}

The required base moment capacity $\mathrm{M}_{\mathrm{b}}$ for each wall was calculated in accordance with the provisions of NZS 4203 (1), based on the 'hand'-calculated fundamental period, and assuming Zone $A$, soft ground conditions. Moment capacities at different levels were then assumed to vary linearly from $1.1 \mathrm{M}_{\mathrm{b}}$ at the base to $0.1 \mathrm{Mb}$ at the top of the wall. This approach, which implies a substantial increase in moment capacity over that required by NZS 4203 for higher levels of the wall, was adopted because recent research by Blakeley et al(11) has demonstrated that significant higher mode jarticipation may occur in the response of shear walls. This research has indicated that the 
distribution of wall moment capacities implied by the code approach may prove to be inadequate, particularly for high shear walls, resulting in hinge-formation at levels above the base, with high ductility demand.

\subsection{Yield Capacity of Energy Dissipators}

The shear capacitor of the energy dissipators should be such that they are not activated under the most severe wind storm likely during the anticipated life of the structure. A base shear capacity of $5 \%$ of the total seismic weight was chosen for Structure A, giving a factor of safety of 2.0 for the 50 year return period wind storm for Christchurch, according to NZS 4203 (1). A capacity of $6 \%$ of total seismic weight was adopted for structures $B$ and $C$ resulting in factors of safety of 1.6 and 1.45 against wind yielding for the eight and twelve storey walls respectively. The choice of approximately 5\% of structural weight for damper capacity agrees closely with values suggested by Skinner and McVerry (4).

\subsection{Basic Analytical Models}

Fig. 5 shows the analytical models for the idealised structures. Model 1 is intended to represent the non-isolated case, assuming there is no base flexibility (foundation compliance). All masses are assumed to be lumped at the floor levels. Masonry material behaviour was represented by bi-linear elasto-plastic hysteresis with a second slope/first slope stiffness ratio of 0.1 , to represent strain-hardening effects. Model 2 (Fig. 5(b)) is felt to be an adequate representation of a base-isolated shear wall, and includes individual representation of the energy dissipator, and the elastomeric bearings. This configuration enabled the influence of vertical flexibility of the elastomeric bearings on structural responses to be investigated. It should be noted that elastomeric bearings supporting the gravity loads will tend to behave in similar fashion to a flexible foundation, reducing fundamental building period. Model 2 also allowed correct simulation of bearing shear stiffness, and facilitated investigations of stability against overturning.

The steel flexural - cantilever dampers were assumed to have a bi-linear elastoplastic hysteresis characteristic, with a ratio of plastic stiffness:elastic stiffness $r=0.05$ typically, based on information supplied by P.E.L. The elastic stiffness was so chosen that a $5 \mathrm{~mm}$ yield displacement was achieved in a $750 \mathrm{~mm}$ high damping device.

As noted above, lead-deformation dampers effectively exhibit rigid-perfectly plastic behaviour. This option was not available from the computer program, and behaviour was approximated by elasto-perfectly plastic behaviour with a very small yield displacement (very high elastic stiffness).

Elastomeric bearings were apportioned a shear stiffness of $.001 \mathrm{~W} / \mathrm{mm}$, where $\mathrm{W}$ is the building weight, as sugges ted by skinner and McVerry (4). Bearing axial stiffness was calculated initially to give a vertical deflection of $3.3 \mathrm{~mm}$ under Dead plus Seismic Live Load. The axial bearing stiffness was later doubled in an attempt to reduce rigid body rotations, as discussed above.

\subsection{Integration Time Step}

The high elastic stiffness of the leaddeformation devices required a comparatively small time step during analysis to ensure that errors due to 'moment-overshoot' corrections were sufficiently small, hence preventing an apparent instability of the integration process occurring with layer time steps. On the basis of a preliminary study into the influence of time-step on the results, a value of $1 / 200$ sec was adopted as being sufficiently accurate, while still economic.

\section{RESULTS OF TIME-HISTORY ANALYSES}

A brief summary of results is included in this section. More complete results are presented in ref. (12).

\subsection{Wall Moments}

Structure A - Four Storey Wall. Period $=0.22 \mathrm{sec}$.

Fig. 6 shows time-histories of moments for different conditions of base-isolation of structure A. The non-isolated wall, Fig. $6(a)$ is subjected to ten yield excursions in the first ten seconds of $E 1$ Centro $1940 \mathrm{~N}-\mathrm{S}$, and as a result of strain hardening, attains a peak base moment of $3260 \mathrm{kNm}, 20 \%$ above the nominal yield level of $2700 \mathrm{kNm}$. Plastic hinges formed at the base, and momentarily at the first floor level, though ductility requirements at this higher level were minimal.

Figs. 6(b) and 6(c) refer to response of the wall when supported on lead energy dissipators and elastomeric bearings designed to the above criteria.

The substantial extent of plasticity required by the devices is clearly shown by the long yield plateaux of device shear force in Fig. $6(\mathrm{~b})$. The actual shear force can be obtained by dividing the moment plotted by the effective length of $125 \mathrm{~mm}$. Note that these periods of dissipator yield at constant force are not accompanied by corresponding periods of constant moment at the wall base (Fig. 6(c)). There are at least three factors contributing to this anomoly.

(1) As the plastic displacement of the energy dissipator increases, the elastic forces due to shear stiffness of the elastomeric bearings become significant, increasing the total effective base shear.

(2) Increased base moments with constant base shear can occur by an increase in overturning moments, inducing axial forces in the elastomeric bearings.

(3) Higher mode effects can superimpose wall moments of significant magnitude onto the basic moments induced by rigid-body translation of the wall as the base-isolation devices yield. Comparison of Figs. $6(\mathrm{~b})$ and 6 (c) shows that these higher mode effects have a significant influence on the response.

As a result of this behaviour, the 
peak base moments induced are larger than might be anticipated on the basis of the shear capacity of the base-isolation system and some assumed distribution of seismic acceleration (often assumed uniform with height for baseisolated structures (4)). The shear capacity of the base isolators was set at 5\% of the seismic weight, corresponding to $16 \%$ of the theoretical capacity of the non-isolated wall. However, peak wall base moment from Fig. $6(\mathrm{c})$ is $1440 \mathrm{kNm}$. Although this represents a substantial reduction from the peak moment attained in the non-isolated wall, the ratio, at $44 \%$ is nearly three times that of the relative base shear capac.. ities.

Fig. 6 (d) shows the time-history of wall base moment using a steel damper, and illustrates the significance of axial stiffness of the elastomeric bearings. With axial stiffness designed to give $3.3 \mathrm{~mm}$ displacement under gravity loads, the maximum moment is $1545 \mathrm{kNm}$. Doubling the axial stiffness results in a maximum moment of onIy $1245 \mathrm{kNm}$. A similar reduction in base moment would occur with the lead deformation isolators, if stiffer bearings were adopted.

Structure B - Eight Storey Wall. Period $=0.95 \mathrm{sec}$.

Time histories for wall moments for Structure B are shown for two cases: nonisolated wall (Fig. $7(\mathrm{a})$ ) and wall isolated with lead-deformation devices (Fig. 7 (b)). Results for steel energy dissipators showed a tendency to develop higher wall base moments than lead devices, due to the significant second slope of the bi-linear hysteresis loop. This effect, noticeable in the results for the four-storey wall, was accentuated in results for structures $B$ and C. Peak values for the steel-cantilever isolated wall are included in Table 1, which summarizes maximum moments and displacements for all walls.

The obvious presence of higher mode participation in the structural response is of particular interest in the plot of the non-isolated eight-storey wall moments (Fig. 7 (a)). Some of the more significant regions where this occurs are arrowed. Peak base moment was $7900 \mathrm{kNm}$, and hinging occurred over a considerable region of the wall. initiating at the fourth floor level on 3 occasions in the first 10 seconds of response. This was despite the conservative nature of wall moment capacity adopted for the structures, as discussed in section 3.1. Maximum curvature ductility demand was 2.7 at the wall base, and 1.6 at the fourthfloor level.

A significant reauction in wall moments was achieved by use of the leaddeformation base-isolation system (Fig. 7 (b)). Maximum wall base moment was reduced to $4869 \mathrm{kNm}$, and the wall remained elastic over its entire height for the full duration of the earthquake record. Higher mode effects are again apparent for the isolated structure, particularly during the long yield excursions that occur at $2.5 \mathrm{sec}$ and $4.5 \mathrm{sec}$.

Structure C - Twelve Storey Wall. Period $=2.20$ sec.

Trends observed in Structure B response were accentuated in the twelvestorey wall. Time histories of the wall moments for non-isolated wall and wall incorporating lead-deformation baseisolation are shown in Fig. 8. Higher mode participation in the non-isolated wall is apparent. Maximum wall base moment is $11500 \mathrm{kNm}$, with a low ductility demand of 1.3. Considerable higher-level hinging occurred, and in fact first hinging initiated at the 7 th and 8 th floors.

Although wall moments are generally reduced by base-isolation, particularly after the first 6 seconds (compare Figs. $8(\mathrm{a})$ and $8(\mathrm{~b}))$, maximum base moment is only reduced by $3 \%$ to $11,140 \mathrm{kNm}$, just initiating hinging at the wall base. Higher mode effects during base-isolator yield are apparent, particularly at 4.5 and 6 seconds.

It is of interest to note that use of a steel-cantilever base-isolation system had the opposite effect to that desired, increasing the base moment by $9 \%$ compared with the non-isolated case, and inducing additional hinging at the first-floor level. Because of the lower design wall moment capacity (resulting from the high building period) and the influence of higher mode effects, hinging occurred at the wall base on one occasion when the isolation system remained elastic.

\subsection{Wall Displacements}

Reductions in relative displacement between roof-level and top of the absorber (i.e. total displacements minus absorber displacements) are of interest, as these give some indication of the likely extent of non-structural damage. Results are presented as time-histories for Structure A (Fig. 9) and are summarized for all structures in Table 1.

Fig. 9(a) shows the roof displacements for the non-isolated four-storey wall. The maximum displacement of $14 \mathrm{~mm}$ represents a structure ductility of 2.3. The relative (roof minus isolator) deflection timehistory for the lead-deformation device is shown in Fig. 9(b). In this case the maximum relative displacement is only reduced from $14 \mathrm{~mm}$ to $10 \mathrm{~mm}$, but of this $10 \mathrm{~mm}, 6.6 \mathrm{~mm}$ is the result of rigid-body rotation of the wall on the flexible elastomeric bearings, implying a structural deformation of only $3.4 \mathrm{~mm}$. Overturning moments induce maximum axial displacements of $\pm 1.47 \mathrm{~mm}$ in the two bearing positions, which is substantially lower than the gravity load deflection of $3.33 \mathrm{~mm}$. Consequently there was an adequate margin of safety against the wall lifting off its bearings.

Relative wall displacements for the cantilever-steel isolation system are plotted in Fig. 9(c) for the two levels of elastomeric bearing axial stiffness investigated. As would be expected, the increase in axial stiffness of the bearings results in a reduction in rigid body rotation of the wall at the base, and hence a reduction in maximum roof displacements. Subtracting rigid-body rotation from the total roof displacement results in maximum structural displacements of $3.7 \mathrm{~mm}$ and $2.9 \mathrm{~mm}$ for the normal and stiffer bearing conditions 
respectively.

For structure A, the computer results indicate that no structural damage should result. Note that in all cases the structural deformations and accelerations have been substantially reduced from the nonisolated case, indicating that non-structural damage should also be substantially reduced, or even eliminated, under seismic attack.

Table 1 indicates that the performance of the eight and twelve storey walls was less satisfactory. The maximum structural displacements of wall $B$ were significantly reduced by the incorporation of base-isolation devices, but the influence on structure $C$ was detrimental, particularly for the wall isolated with steel-cantilever devices.

It is also of interest to examine the extent of plastic deformation sustained by the energy dissipators. This information is included in Table 1. It will be noted that maximum base displacements for Structures $A$ and $B$ are similar, at about $65 \mathrm{~mm}$, but Structure $C$ sustained base deformation in the vicinity of $120 \mathrm{~mm}$. These levels are acceptable for current designs of isolators $(5,6)$.

Results showed that elastomeric bearings had a significant centering effect, substantially reducing the final base drift. Maximum number of yield excursions experienced during the first ten seconds of El Centro was only 22 . Work by Skinner et al $(5,6)$ has shown that fatigue failure can not be expected until several hundred cycles to full design displacement have taken place.

\section{DISCUSSION OF RESULTS}

\subsection{Required Flexural Capacity of Walls}

One of the main advantages of baseisolation is that it enables the designer to proportion the isolated structure for lower moments and shears. Past research(4) has suggested that the dynamically calculated base shear may be distributed in direct proportion to the floor masses. It appears that this assumption is based on results of single-degree-of-freedom systems, and the observation that the large displacements of the energy absorbers compared with the structure deformations relative to the base effectively make all floor displacements equal. It is traditional to design structures for inertia forces proportional to the shape of the first mode deflections.

It is, however, apparent from the results of the multi-degree-of-freedom analyses presented above that the design levels for moment and shear are not directly set by the capacity of the base-isolation system, as higher mode effects are particularly significant. Although all floor displacements may be effectively equal at a given time, the difference in frequency between the low frequency response due to isolator deformation, and the superimposed higher mode structural response (typically a factor of 10 in the examples above) implies that the small differences in floor displacements represent large differences in floor accelerations. Assuming a higher mode displacement of $1 \%$ of the base-isolation displacement, inertia forces from the higher mode $\left(F_{h}\right)$ will be related to inertia forces from base-isolation displacement $\left(\mathrm{F}_{\mathrm{b}}\right)$ by the relationship

$$
\begin{aligned}
\frac{F_{h}}{\bar{F}_{b}} & =\frac{w_{h}^{2} \times 0.01}{w_{b}^{2} \times 1} & \text { where } w_{h}=\begin{array}{l}
\text { higher mode } \\
\text { frequency }
\end{array} \\
& \simeq \frac{100 \times .01}{1 \times 1} & w_{b}=\begin{array}{l}
\text { effective fre- } \\
\text { quency of isolator } \\
\text { displacements }
\end{array} \\
& =1.0 & w_{h} / w_{b} \simeq 10
\end{aligned}
$$

Thus the inertia forces from higher mode effects are likely to be of equal significance to those induced by the baseisolator displacements. Inspection of Figs. $9(\mathrm{~b})$ and $9(\mathrm{c})$, and comparison with the maximum displacements of the baseisolator (Table 1) clearly shows that relative higher mode displacements substantially higher than the $1 \%$ assumed above have occurred.

Fig. 10 compares moment envelopes obtained from the computer analyses of the three structures, with theoretical envelopes based on various assumptions. The envelopes are plotted against fraction of wall height for convenience of comparison. Lines 1 and 2 represent envelopes for the walls isolated by lead and steel devices respectively. Line 3 represents the design envelope according to NZS 4203(1) (note that higher wall moment capacities were adopted, as mentioned in section 3.1 above). Lines $4 \mathrm{~A}$ and $4 \mathrm{~B}$ show envelopes obtained from distribution of the base-isolator capacity in proportion to floor masses, as suggested by Skinner and McVerry (4)! The base-isolator capacity is defined here as the maximum shear from computer analysis at the level of the energy absorber, including strain-hardening effects and the shear contribution from the elastomeric bearings. Lines 5 and 6 represent envelopes obtained when the base shear is distributed in proportion to floor mass, for lead and steel devices respectively. Base shear is defined as the maximum shear in the wall between ground and first floor, and thus corresponds to the conventional definition adopted for non-isolated structures. The base-isolator capacity and base shear differ by an amount equal to the inertia force of the ground floor masses. It will be observed that the base-isolator capacity is smaller than the base shear, indicating that the ground floor accelerations reduce absorber force at the critical time, again showing the significance of higher mode effects. For completeness, the results for the nonisolated walls are included.

Several points are immediately obvious from these moment envelopes.

(1) For non-isolated walls, the influence of higher mode participation becomes increasingly important as the building period increases, and the distribution of moments according to NZS 4203 (1) becomes increasingly non-conservative. This confirms findings reported by Blakeley et al(11).

(2) Reduction in wall moments afforded by base-isolation is substantial for the short period Structure A, but minimal for Structure C. This is in part a result of the lower seismic design coefficients for the non- 
isolated long-period structures, coupled with the higher base-isolator capacity necessitated to provide adequate protection against wind load. It is also felt that higher mode effects are more significant in the response of longer period structures.

(3) Lead-deformation devices result in greater reduction of wall moments than cantilever-steel devices.

(4) Distribution of the base-isolator capacity, or maximum base shear, in proportion to floor mass results in a severe underestimation of the required capacity for Structures A and B, and produces an envelope for Structure $C$ which is conservative close to the base of the wall but non-conservative higher up the wall.

\section{DESIGN RECOMMENDATIONS}

Thus it appears there is no simple way of relating required wall moment capacity to base-isolator shear capacity. It is further apparent that an 'equal-acceleration' approximation for floor masses is inappropriate. Fig. 10 suggests that a straight-line moment distribution would be suitably conservative. Pending the results of further research it is tentatively suggested that design recommendations may be made on the basis of the results of this report, as follows. The discussion is limited to short to intermediate period structures (period less than 1.0 sec.) as results do not indicate advantages for incorporating devices in long-period structures.

(1) Lead-deformation devices are preferable to cantilever-steel devices.

(2) Yield capacity of the base-isolation device should be about 5\% of building weight, but calculations should establish that this gives adequate protection against yield under the 50 year design wind storm.

(3) The wall base moment $M_{b}$ should be calculated using the approach required by the loadings code(1), namely

$$
\begin{aligned}
\text { Base shear : } \mathrm{V}=\mathrm{C}_{\mathrm{d}} \mathrm{w}_{t} & \text { Eqn. (27) of ref. } 1 \\
\text { where } \mathrm{C}_{\mathrm{d}}=\mathrm{CISMR} & \text { Eqn. (28) of ref. } 1
\end{aligned}
$$

using the nomenclative of ref. 1. However, it is felt that the structural type factor $S$ and material factor $M$ may both be set equal to unity, since structural yield is avoided. There is also a strong case for putting $I$ and $R$ at unity, or at least substantially reducing their current values. Note that in general this will then imply that $\mathrm{C}_{\mathrm{d}}=\mathrm{C}$.

(4) Wall moment capacities should be provided to satisfy a linear requirement from $M_{b}$ at the wall base to $0.1 M_{b}$ at the top of the wall. For masonry structures, a flexural undercapacity factor of $\phi=0.85$, as suggested by Priestley(3), should be adequate.

(5) The design shear force distribution should be found by distributing the base shear force $V$ (as above) in accordance with NZS 4203(1), with an additional $0.2 \mathrm{~V}$ applied at the roof level to cover shear force distributions resulting from higher modes. The shear force distributions of Fig. Il show that this gives adequate protection for structure A.

(6) Elastomeric bearing pads used to support gravity loads should have high axial stiffness to reduce rigid-body racking displacements, and low shear stiffness to reduce total base-isolator shear capacity.

Design to these requirements provides an adequate wall capacity for shear and flexure for Structures $A$ and $B$. Note that the above recommendations represent a moderate decrease in design wall moments, and a much greater decrease in design shear forces, which do not need to be calculated on the basis of a flexural overcapacity approach. For a short period masonry structure with squat shear walls located in Zone $A$, the recommendations would represent a reduction from $0.288 \mathrm{~g}$ to $0.16 \mathrm{~g}$ for seismic coefficient for flexural strength calculations, and a reduction from up to $0.60 \mathrm{~g}^{3}$ to $0.18 \mathrm{~g}$ for seismic coefficient for shear strength calculations.

\section{CONCLUSIONS}

Results of analyses of short, intermediate and long-period masonry structures incorporating base-isolation systems indicate that elimination of wall hinging, and significant reduction of wall forces will only result for structures with building periods less than about $0.8 \mathrm{sec}$. For very long period structures, behaviour can be affected detrimentally, with an increase in ductility demand resulting from the incorporation of base-isolation.

Dynamic response of the isolated walls was more complex than previously believed, largely due to the influence of higher mode effects on the wall moments. Analysis using multi-degree-of-freedom models was essential to investigate the higher mode phenomena.

Characteristics of elastomeric bearing pads used to support gravity loads have a profound influence on the structural response. careful design is necessary to obtain optimum performance under seismic conditions.

Tentative recommendations for design made in the paper are felt to be satisfactory interim measures, but it is emphasized that more research is needed to investigate the response of base-isolated structures in greater depth, before firm recommendations can be made.

\section{ACKNOWLEDGE'MENT}

The work described in this report was carried out at the University of Canterbury as an M.E. project by R. L. Crosbie, supervised by M.J.N. Priestley and A.J. Carr. Grateful acknowledgement is made of financial assistance provided by the New Zealand Pottery and Ceramics Research Association.

\section{REFERENCES}

1. "Code of Practice for General Structural Design and Design Loadings for Buildings", N.Z.S. 4203, 1976, Standards Association of N.Z. 
2. "Draft of Design Section of Proposed Masonry Code", DZ 4210, Standards Association of N.Z.

3. Priestley, M.J.N., "Seismic Resistance of Reinforced Concrete-Masonry Shear Walls with High Steel Percentages", Bull. N.Z. Soc. for Earthquake Engineering, Vol. 10, No. 1, March 1975, pp.1-16.

4. Skinner, R. I., and McVerry, G.H.,

"Base Isolators for Increased Earthquake Resistance of Buildings", Bulletin of N.Z. Society for Earthquake Engineering,

Vol. 8, No. 2, 1975, pp. 93-101.

5. Kelly, J.M., Skinner, R.I. and Heine, A.J., "Mechanisms of Energy Absorption in Special Devices for Use in Earthquake Resistant Structures", Bulletin of

N.z. Society for Earthquake Engineering, Vol. 5, No. 3, Sept. 1972, pp.63-88.

6. Skinner, R.I., Kelly, J.M. and Heine, A.J., "Hysteretic Dampers for Earthquake Resistant Structures", Earthquake Engineering and Structural Dynamics, Vol. 3, 1975, pp. 282-296.

7. Robinson, W.H., Greenbank, L.R., "Properties of an Extrusion Energy Absorber", Bulletin of N.Z. Society for Earthquake Engineering, Vol. 8,
No. 3, sept. 1975.

8. Robinson, W.H., Greenbank, L.R., "An Extrusion Energy Absorber Suitable for the Protection of Structures During an Earthquake", Earthquake Engineering and Structural Dynamics, Vol. 4, 1976, pp. 25l-259.

9. Sharpe, R.D. "The Seismic Response of Inelastic Structures", Ph.D Thesis, University of Canterbury, 1974 (Research Report 74-13) 126 pages.

10. Taylor, R.G., "The Non-linear Seismic Response of Tall Shear Wall Structures", Ph.D. Thesis, University of Canterbury, to be published.

11. Blakeley, R.W.G., Cooney, R.C. and Megget, L.M., "Seismic Shear Loading at Flexural Capacity in Cantilever Wall Structures". Bulletin of N.Z. Society for Earthquake Engineering, Vol. 8, No. 4, December, 1975, pp. 278-290.

12. Crosbie, R.L., "Base Isolation for Brick Masonry Cantilever Shear Wall Structures", M.E. Project Report, University of Canterbury, Research Report 77-2, Feb. 1977, 186 pages.

13. Robinson, W.H., - Personal communication.

TABLE 1

SUMMARY OF BEHAVIOUR

\begin{tabular}{|c|c|c|c|c|c|c|}
\hline STRUCTURE & $\begin{array}{l}\text { COMP } \\
\text { MODEL }\end{array}$ & $\begin{array}{l}\text { MAX. BASE } \\
\text { MOMENT kNm }\end{array}$ & $\begin{array}{l}\text { MAX. } \\
\text { DISP }\end{array}$ & $\begin{array}{l}\text { LATIVE } \\
(\mathrm{mm})\end{array}$ & $\begin{array}{cc}\text { MAX. } & \text { BASE } \\
\text { DISP. } & (\mathrm{mm})\end{array}$ & $\begin{array}{rr}\text { MAX. } & \text { ROOF } \\
\text { DISP. } & (\mathrm{mn})\end{array}$ \\
\hline \multirow{4}{*}{$\begin{array}{c}\text { A } \\
(4-\text { Storey })\end{array}$} & 1 & 3260 & \multicolumn{2}{|c|}{13.9} & N.A. & 13.9 \\
\hline & $2 \mathrm{~s}$ & 1545 & 10.9 & $(3.7)$ & 67.6 & 73.8 \\
\hline & $2 s *$ & 1245 & 5.8 & $(2.9)$ & 72.4 & 77.4 \\
\hline & $2 \mathrm{~L}$ & 1440 & 10.0 & $(3.4)$ & 64.6 & 68.6 \\
\hline \multirow{3}{*}{$\begin{array}{c}\text { B } \\
(8-\text { Storey })\end{array}$} & 1 & 7897 & \multicolumn{2}{|c|}{137} & N.A. & 137 \\
\hline & $2 \mathrm{~s}$ & 6776 & 69 & (56) & 62 & 113 \\
\hline & $2 \mathrm{~L}$ & 4861 & 45 & (33) & 73 & 116 \\
\hline \multirow{3}{*}{$\begin{array}{c}\text { C } \\
(12-\text { Storey })\end{array}$} & 1 & 11505 & \multicolumn{2}{|c|}{202} & N.A. & 202 \\
\hline & $2 \mathrm{~s}$ & 12507 & 360 & $(340)$ & 134 & 453 \\
\hline & $2 \mathrm{~L}$ & 11140 & 232 & $(214)$ & 113 & 326 \\
\hline
\end{tabular}

NOTE: 1. Comp. Model $1=$ non-isolated

$$
\begin{aligned}
& =2 \mathrm{~s}= \\
2 \mathrm{~s}^{*} & =\begin{array}{l}
\text { steel-cantilever isolated } \\
\text { stiffness }
\end{array} \\
2 \mathrm{~L} & =\text { lead-deformation isolated. }
\end{aligned}
$$

2. Displacements due to structural deformation of wall only (ignoring rigid body rotation of wall on bearings) are shown in parenthesis. 


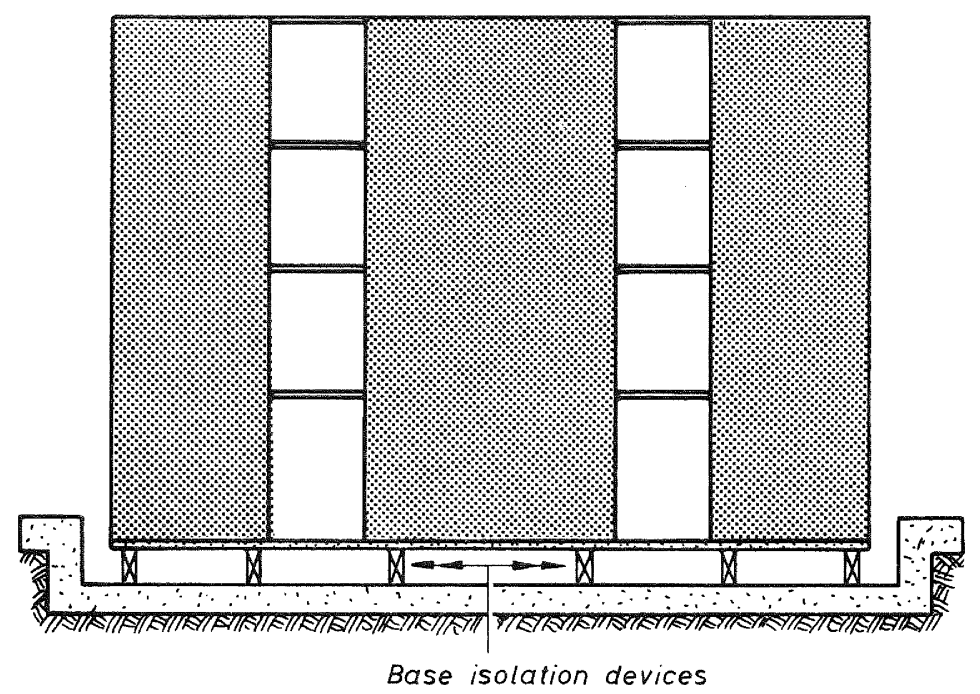

FIGURE 1: MASONRY SHEAR WALL BUILDING SUPPORTED ON MECHANICAL ENERGY DISSIPATORS

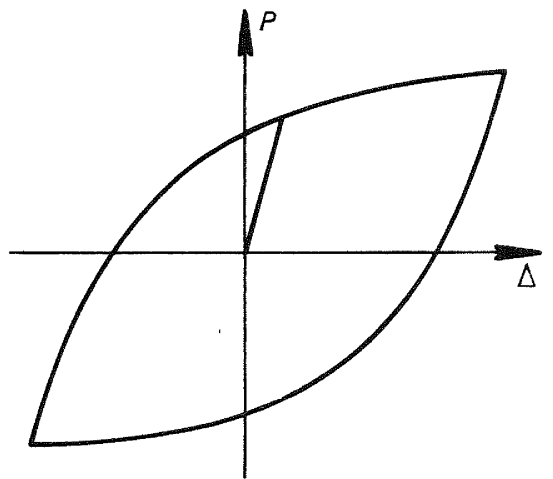

(a) Ramberg - Osgood

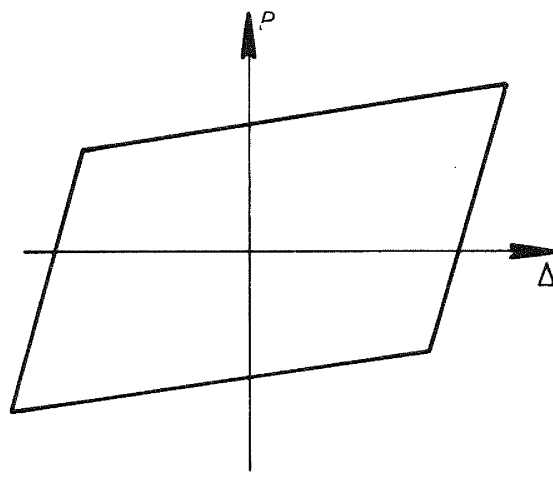

(b) B1-Linear Elasto Plastic

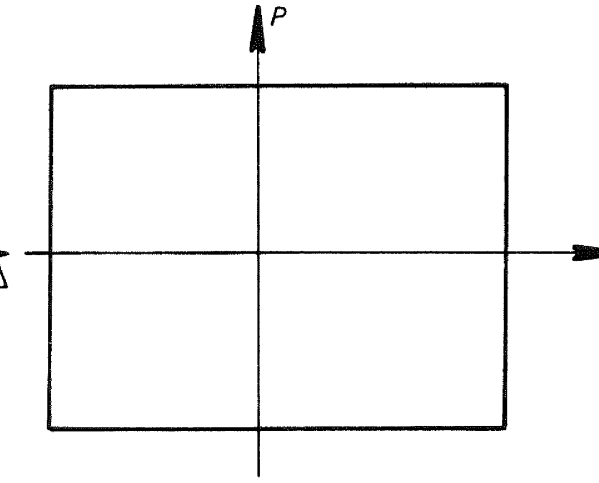

(c) Rigid-Perfectly Plastic

FIGURE 2: LOAD - DEFLECTION HYSTERESIS TYPES

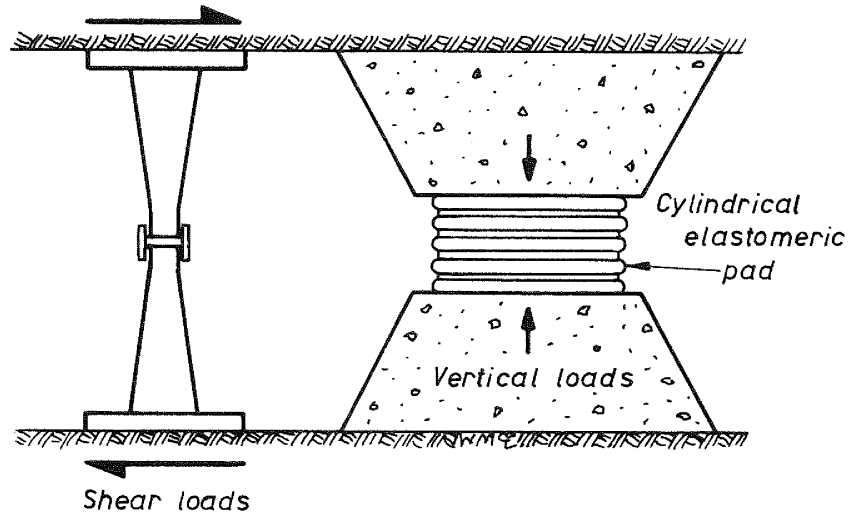

FIGURE 3: BASE - ISOLATION USING STEEL

CANTILEVERS AND ELASTOMERIC BEARINGS 

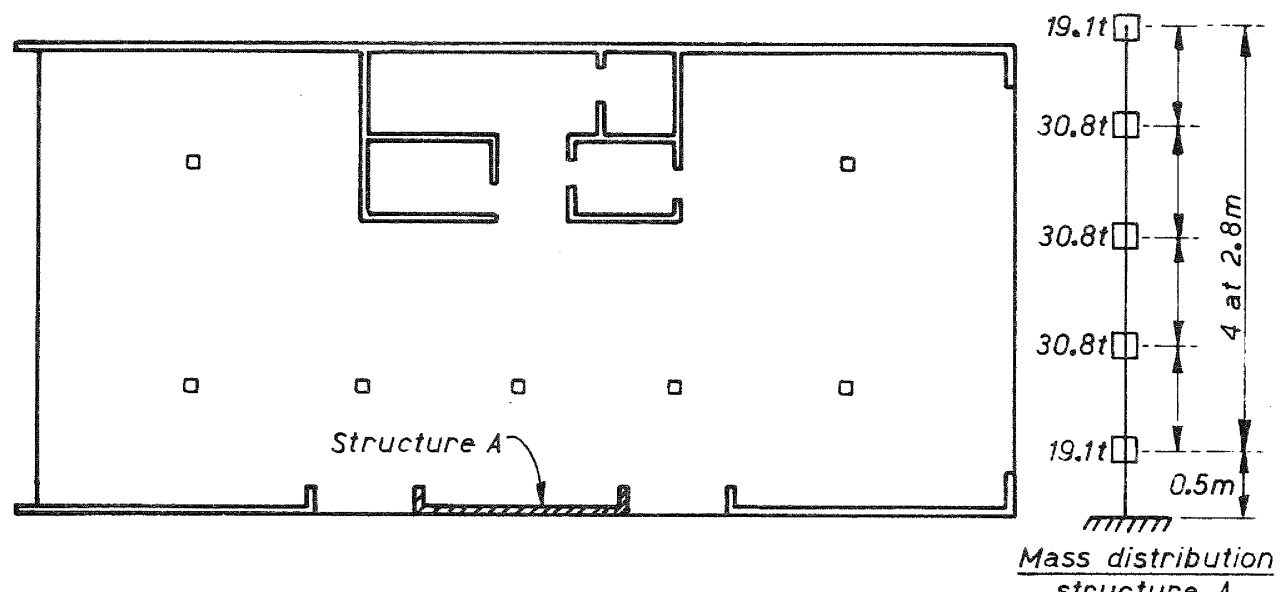

(a) FLOOR PLAN, 4 STOREY MASONRY BUILDING

structure $A$

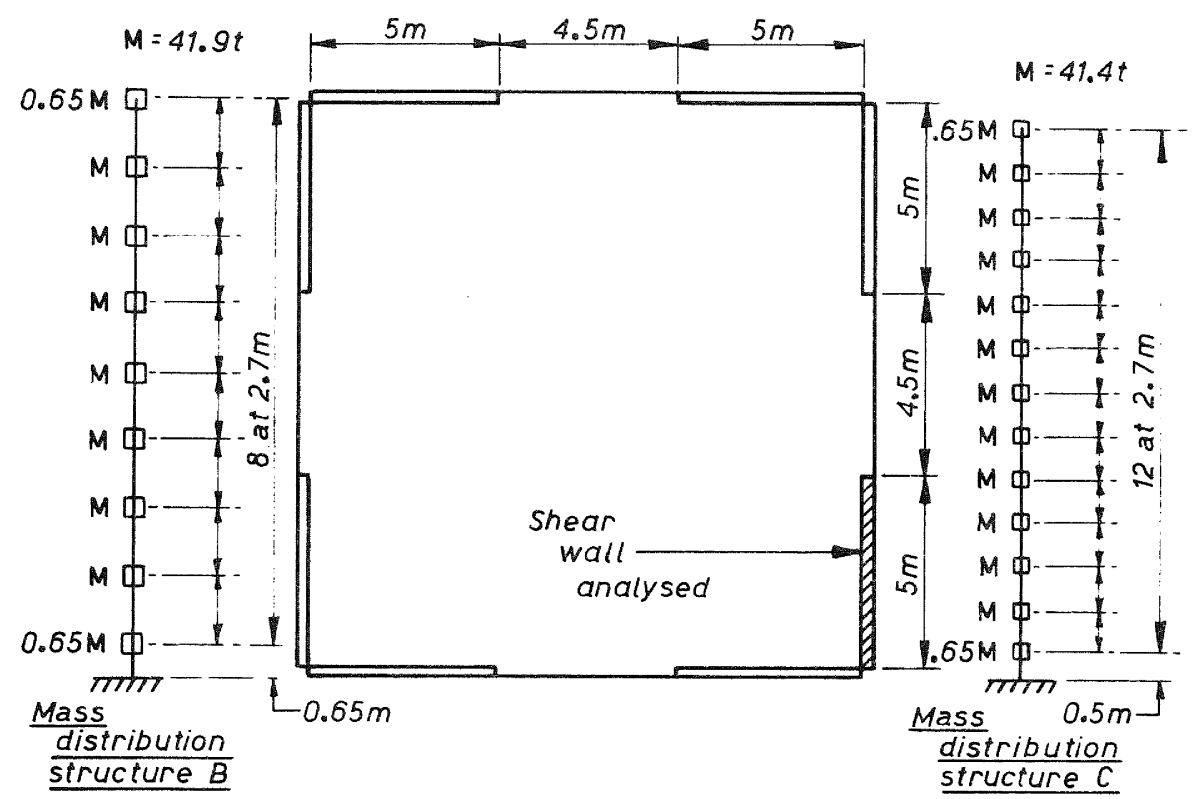

(b) FLOOR PLAN, 8 and 12 STOREY MASONRY BUILDINGS.

FIGURE 4: WALLS ADOPTED FOR ANALYSIS

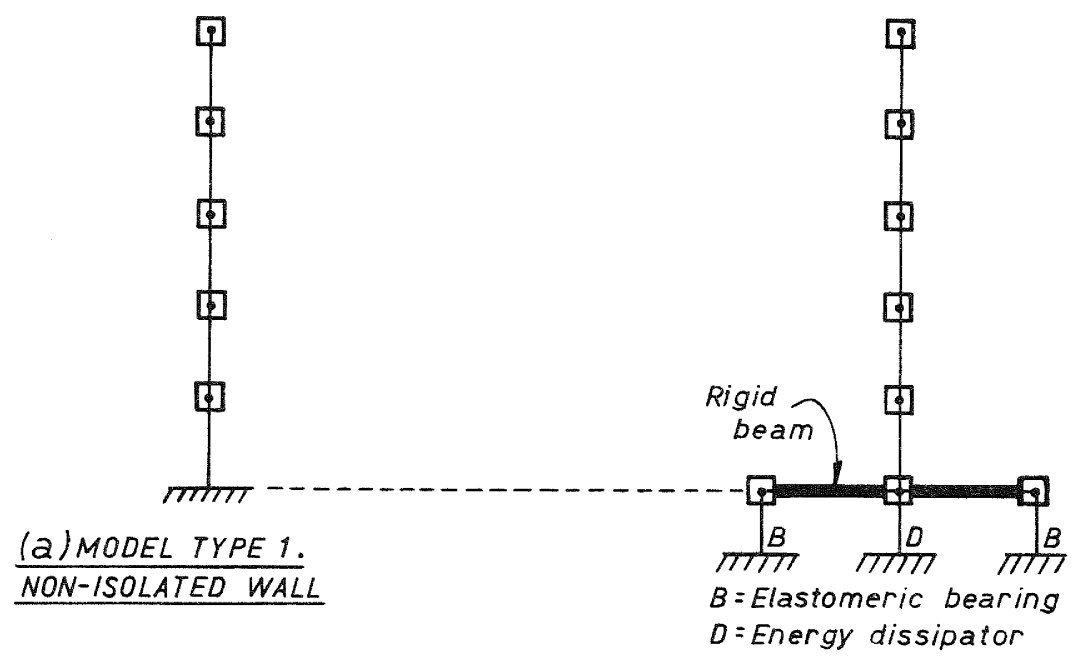

(b) MODEL TYPE 2.

BASE ISOLATED WALL 


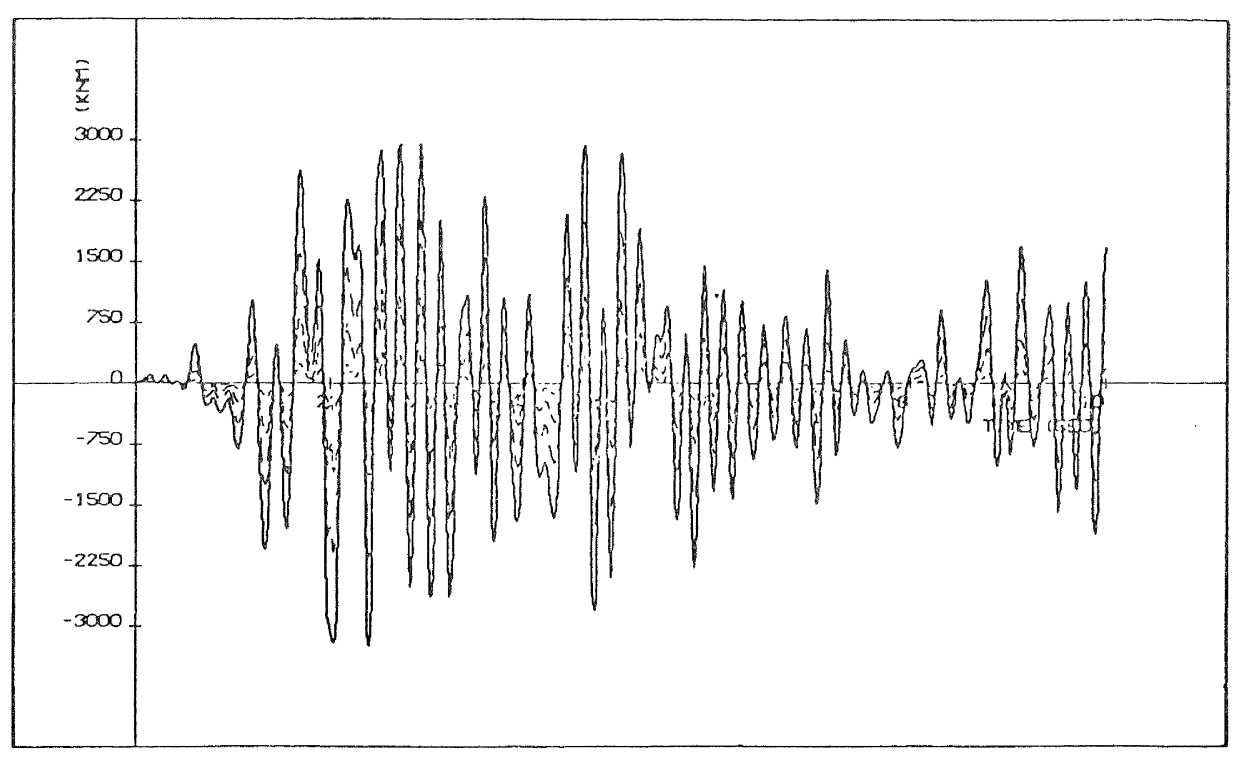

(a) WALL BASE MOMENT FOR NON-ISOLATED WALL

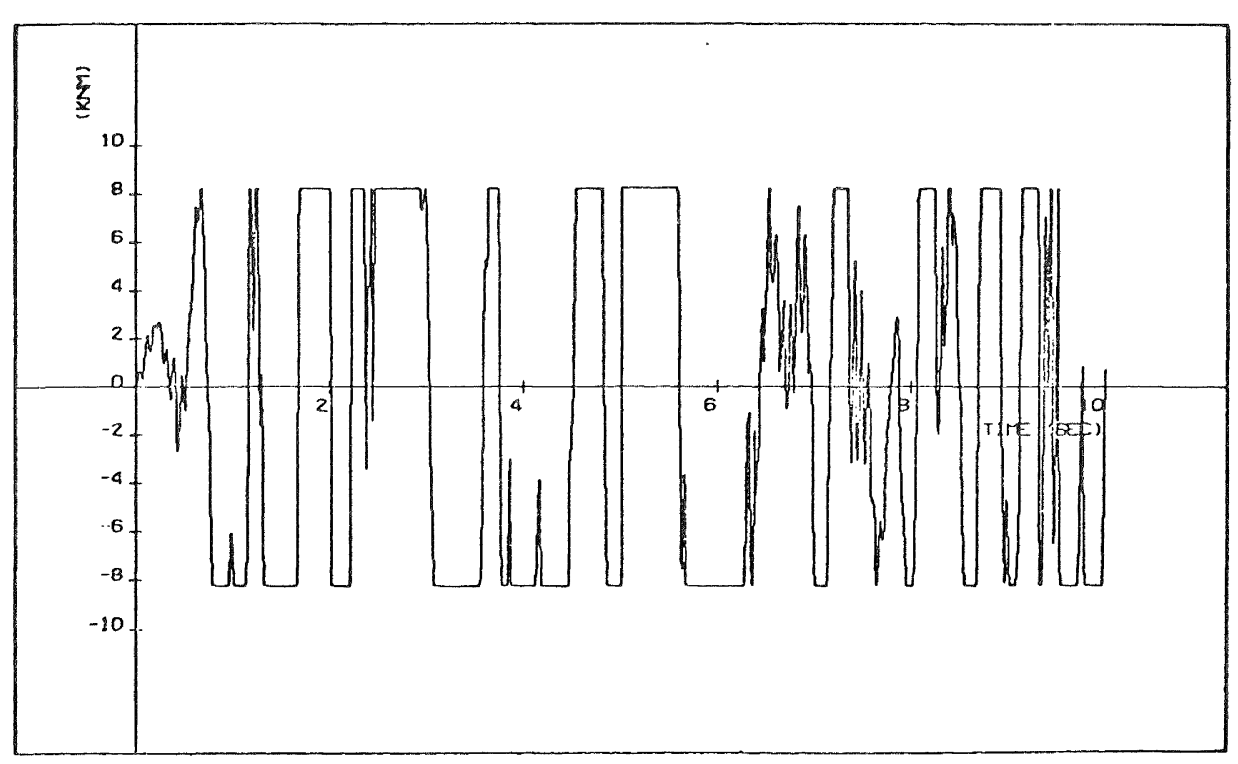

(b) SHEAR FORCE IN LEAD DEVICE

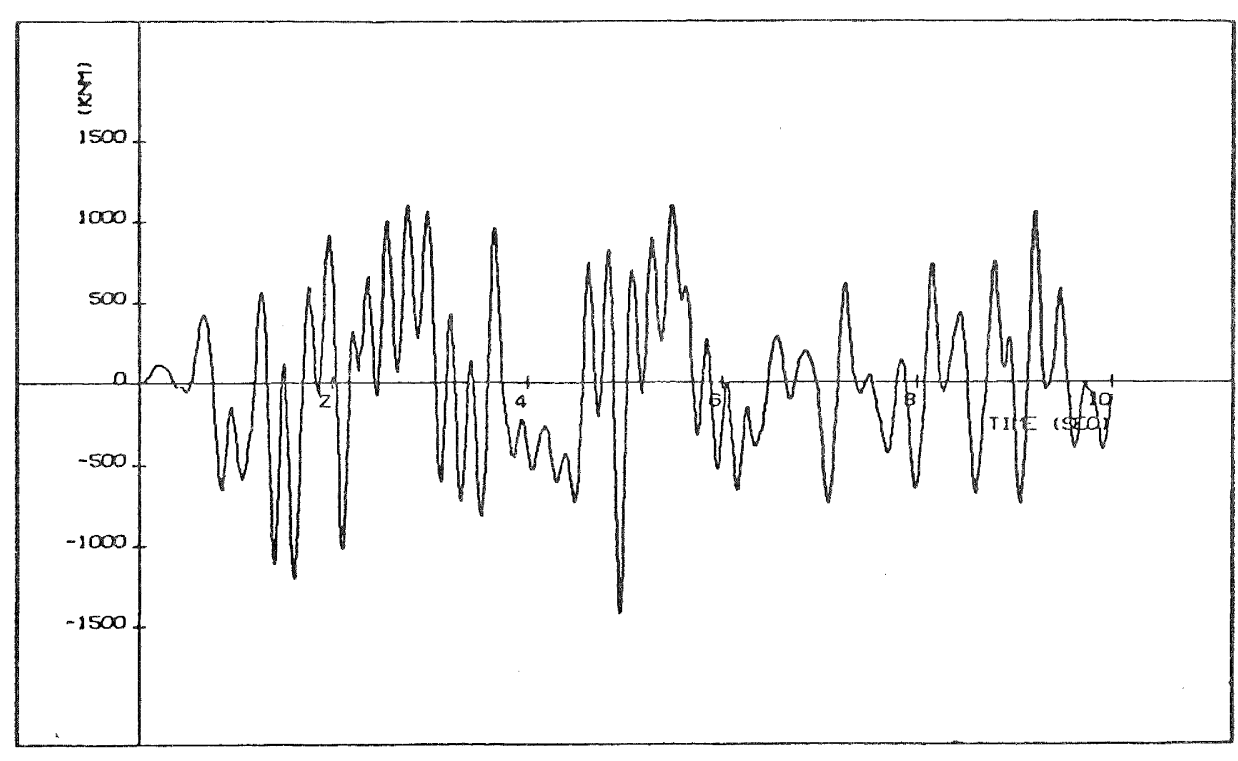

(c) WALL BASE MOMENT FOR LEAD ISOLATION

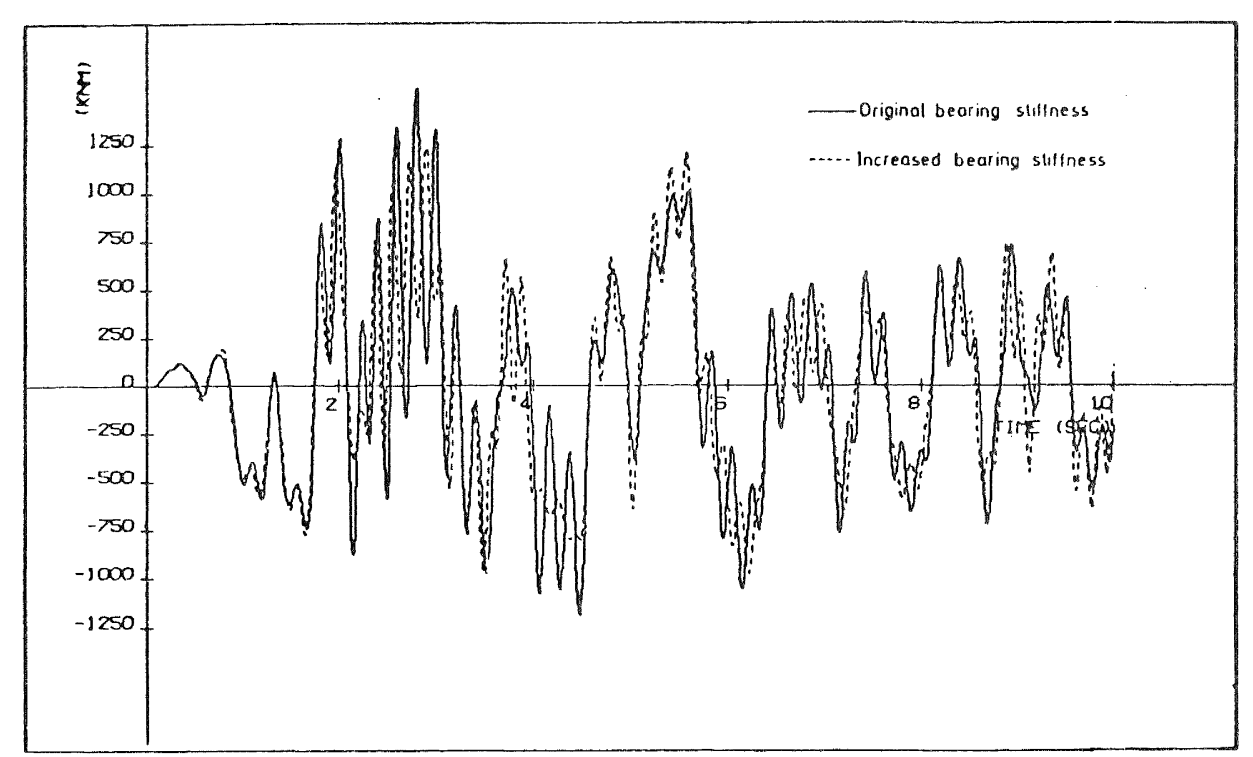

(d) WALL BASE MOMENT FOR STEEL-CANTILEVER ISOLATION 


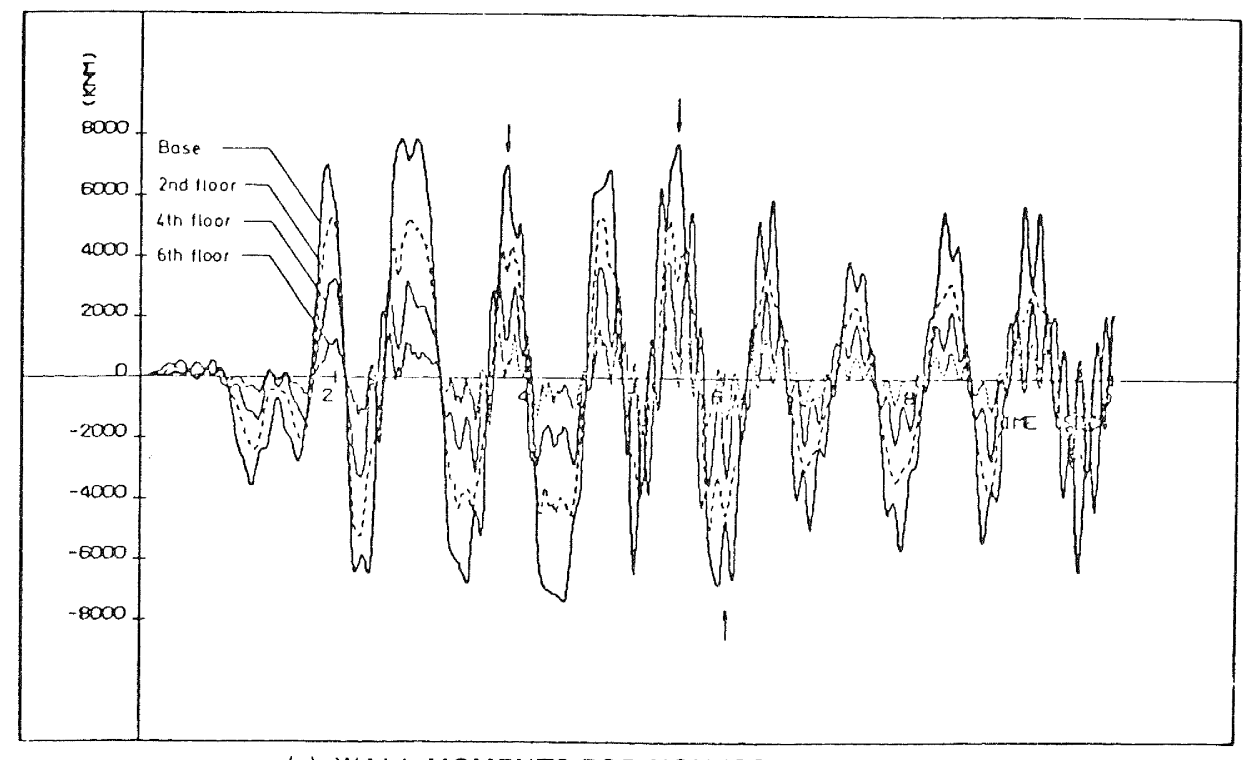

(a) WALL MOMENTS FOR NON-ISOLATED WALL

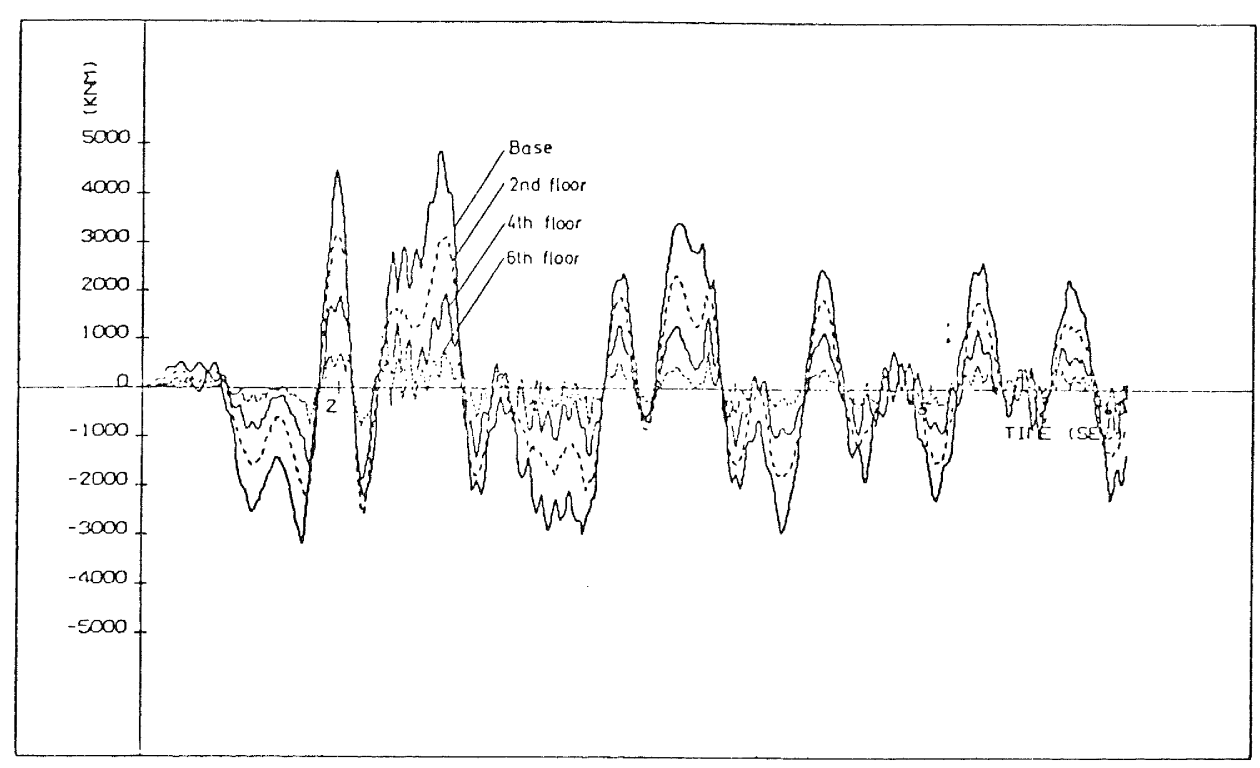

(b) WALL MOMENTS FOR LEAD ISOLATION

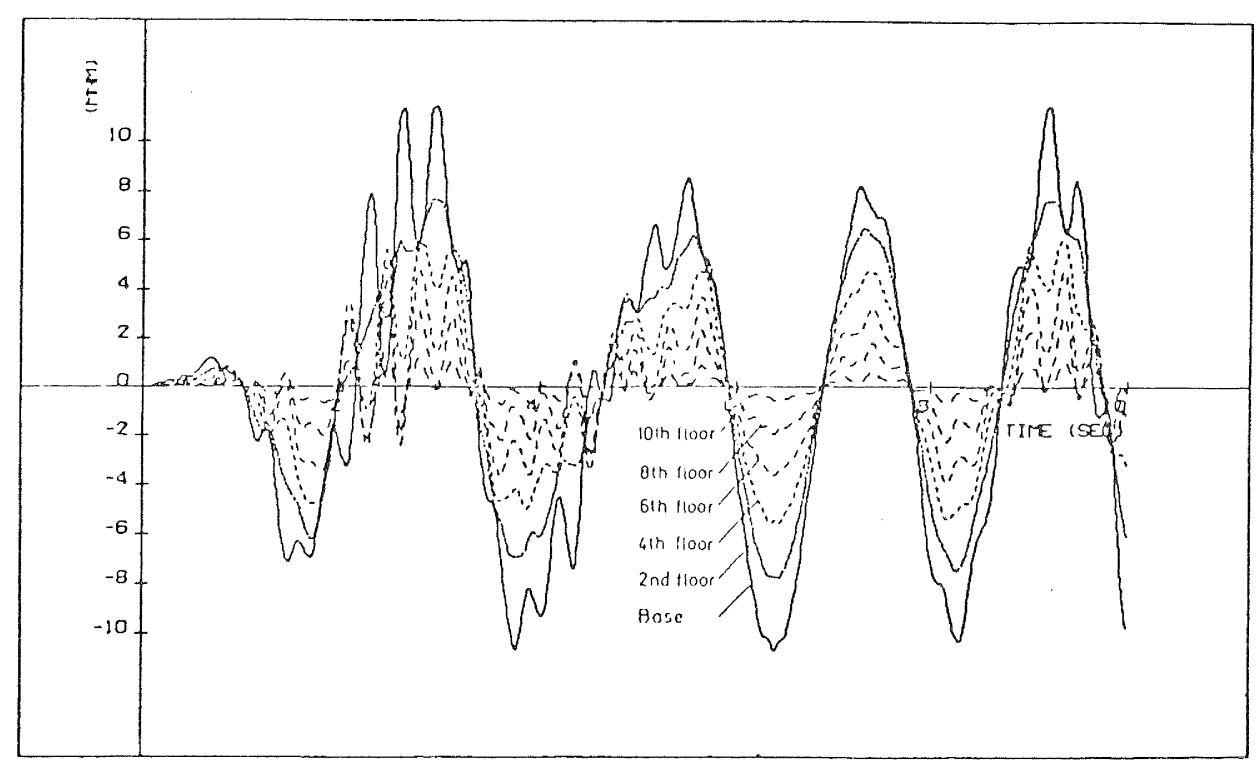

(a) WALL MOMENTS FOR NON-ISOLATED WALL

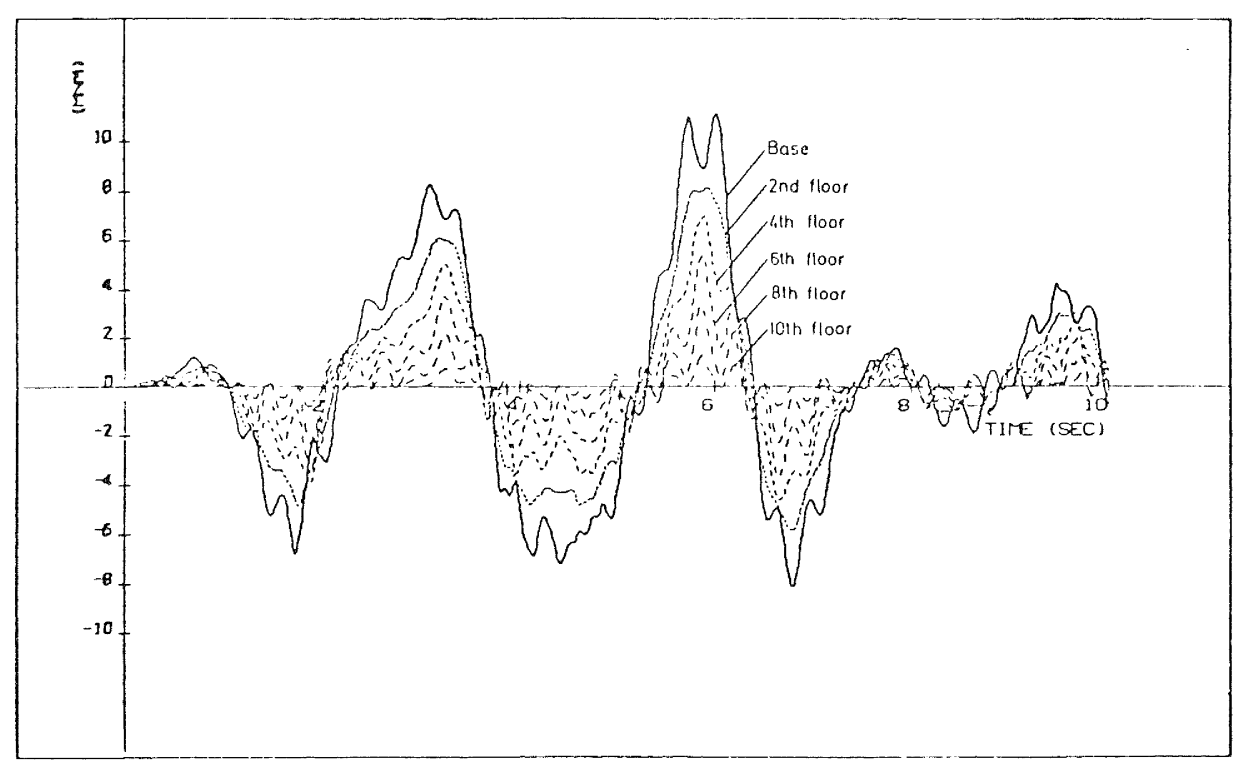

(b) WALL MOMENTS FOR LEAD ISOLATION 


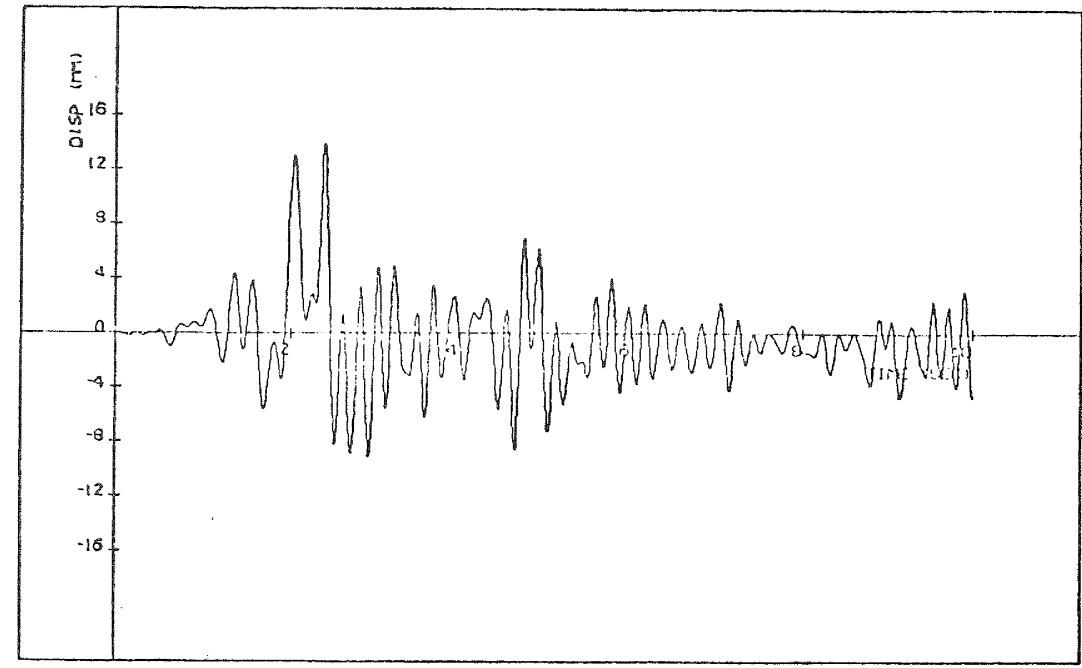

(a) NON-ISOLATED WALL

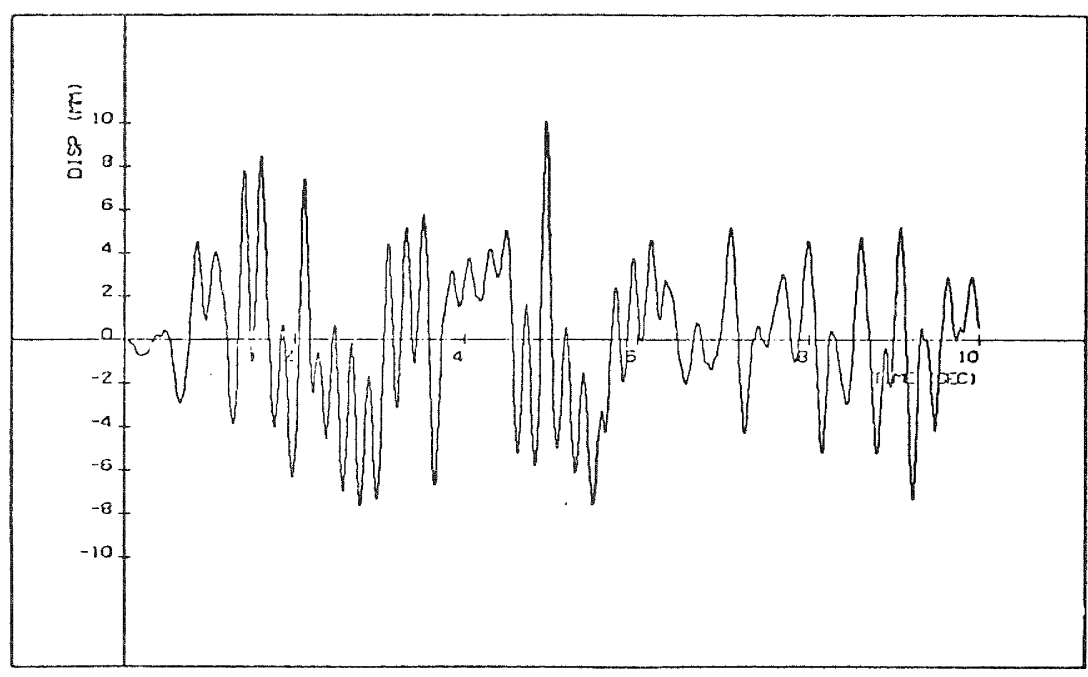

(b) WALL WITH LEAD ISOLATION

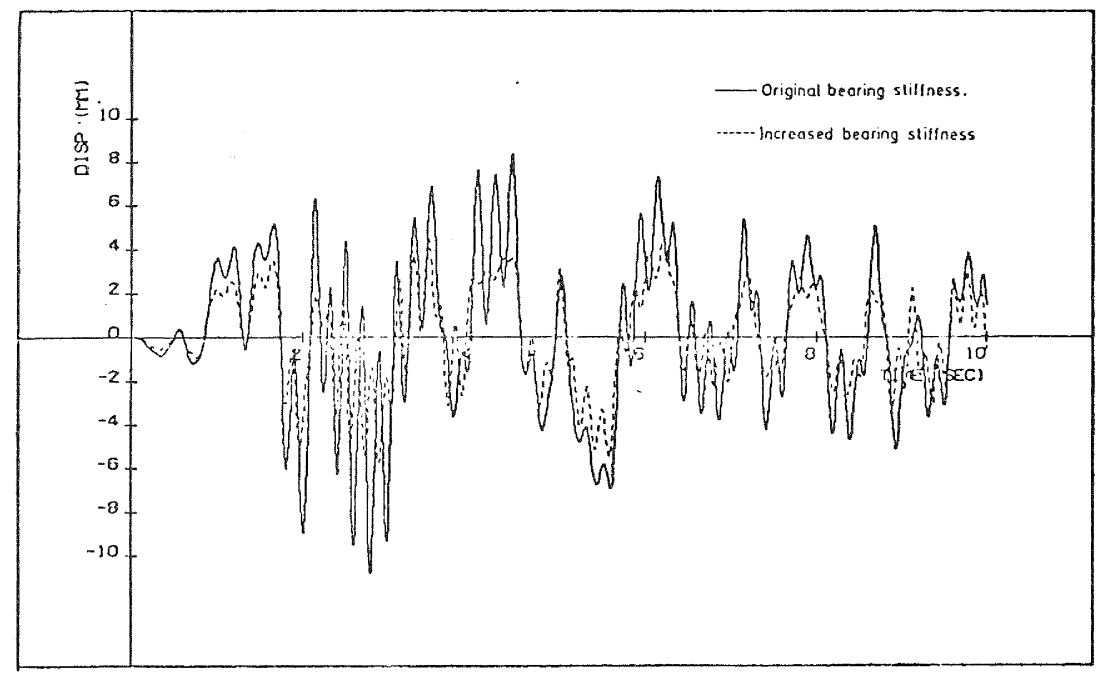

(c) WALL WITH STEEL-CANTILEVER ISOLATION 
FOUR-STOREY WALI

\section{Legend}

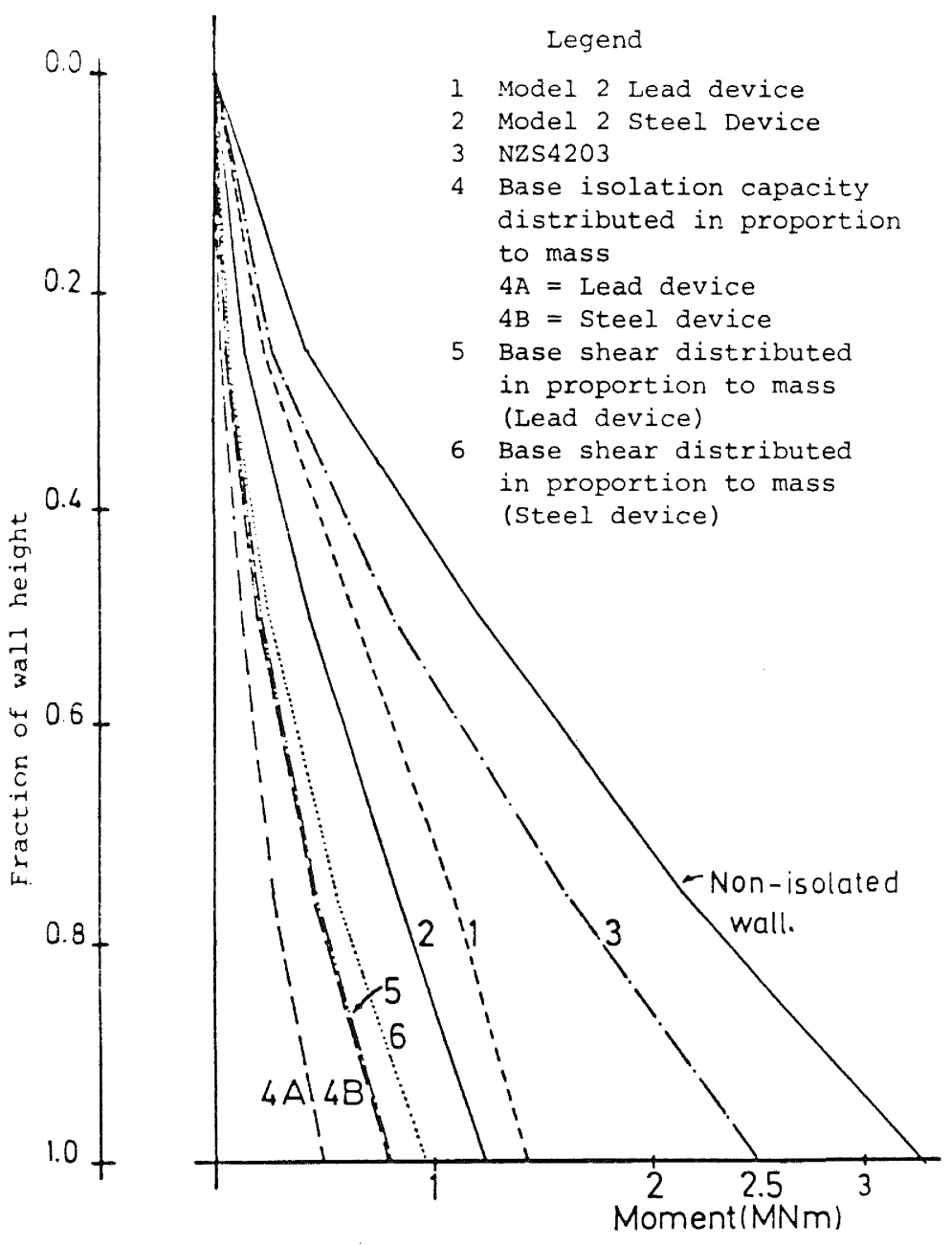

EIGHT-STOREY WALL

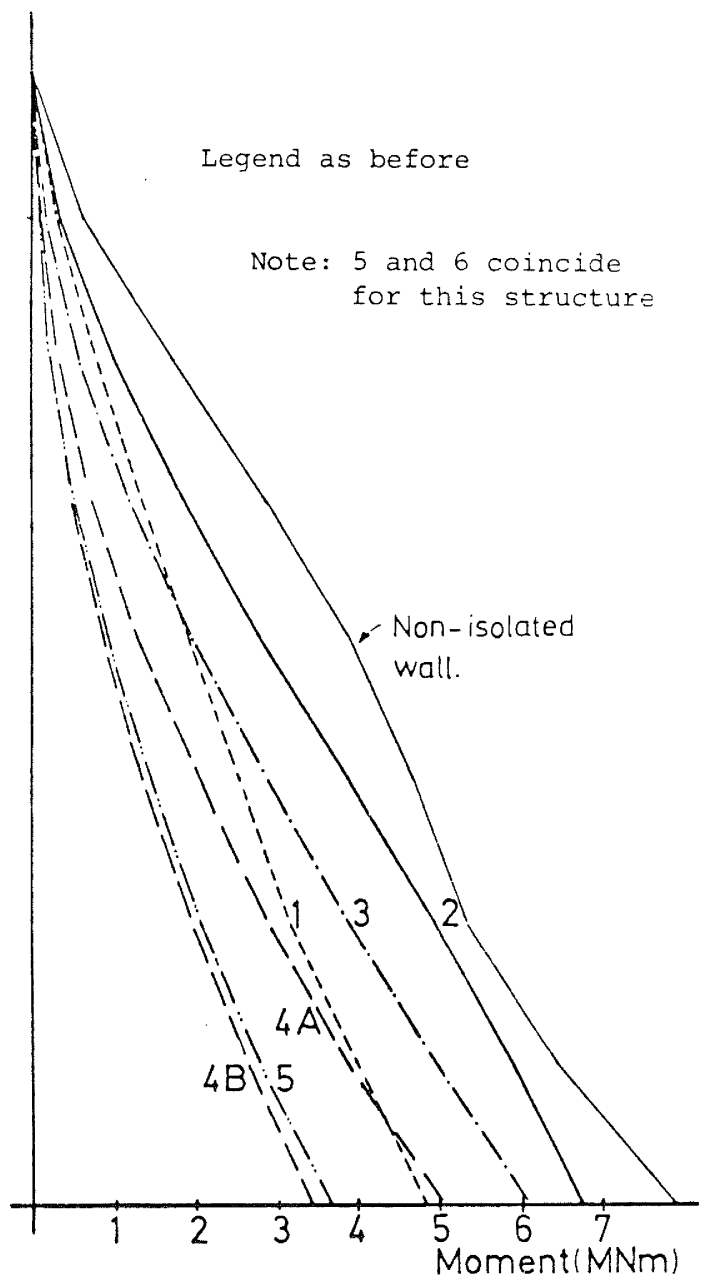

TWELVE-STOREY WALI

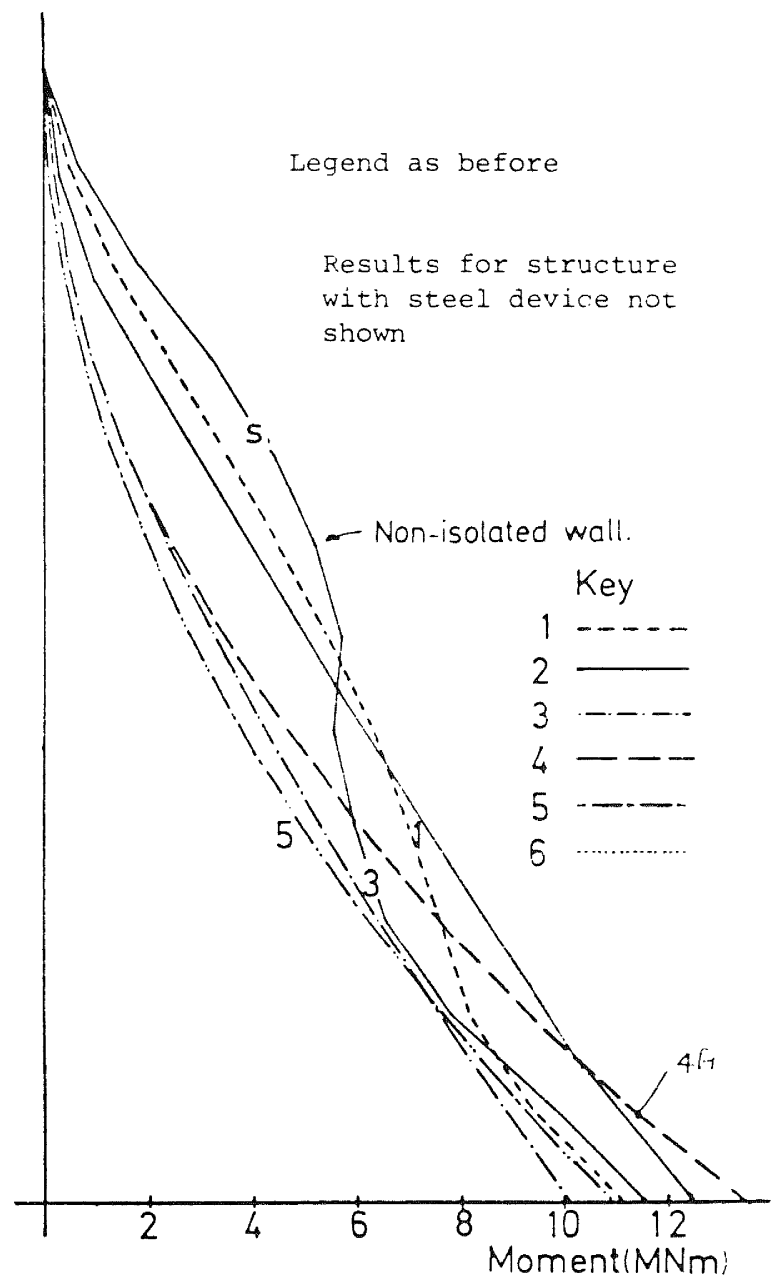

FIGURE 10: COMPARISON OF MOMENT ENVELOPES 


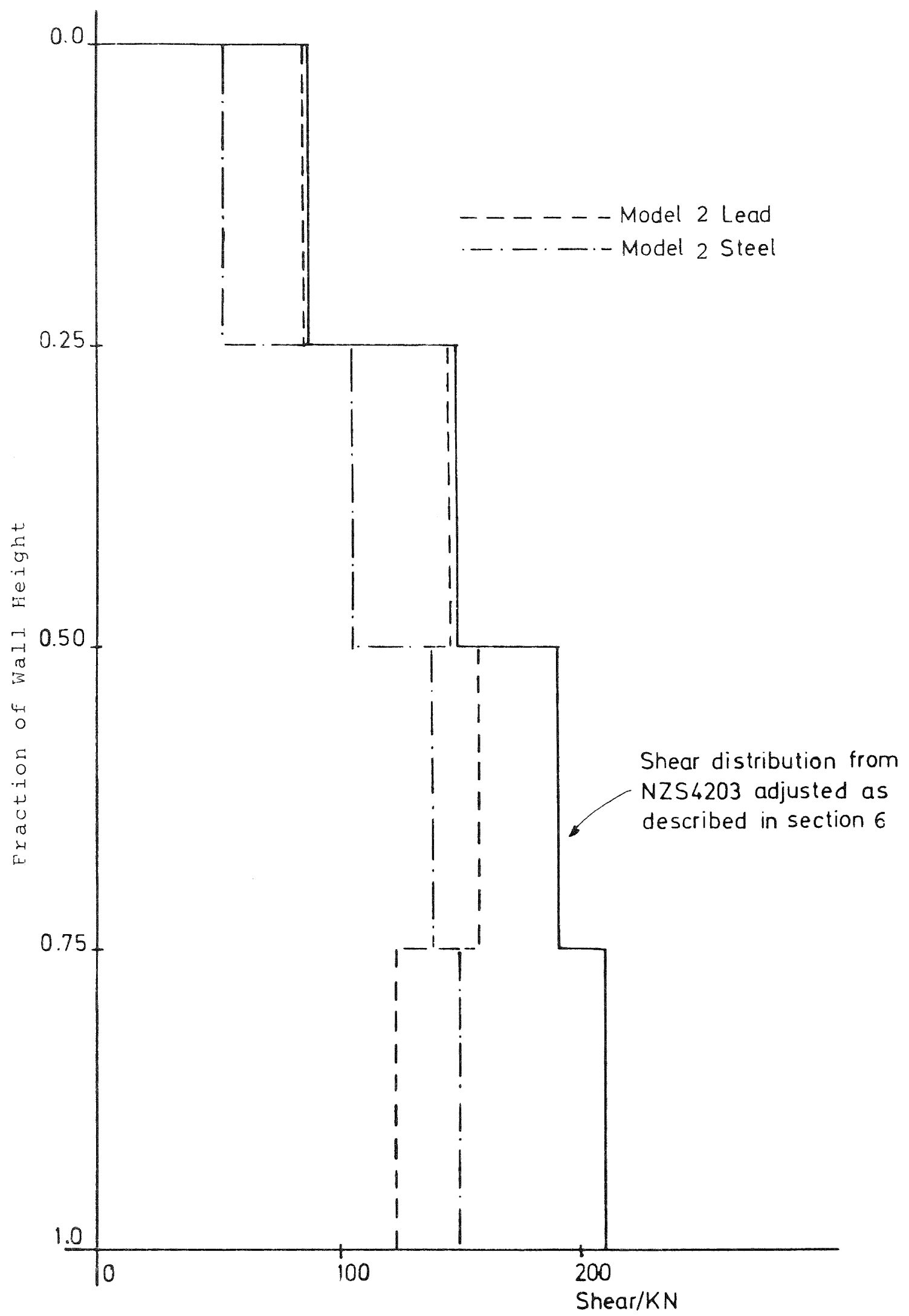

FIGURE 11: FOUR-STOREY WALL: STOREY SHEARS 